\title{
Association between Restriction Fragment Length Polymorphism of the Human Cytochrome P450IIE1 Gene and Susceptibility to Lung Cancer
}

\author{
Fumiyuki Uematsu, ${ }^{1,2}$ Hideaki Kikuchi, ${ }^{1}$ Masakichi Motomiya, ${ }^{2}$ Tatsuya Abe, ${ }^{2}$ Ikuko \\ Sagami, ${ }^{1}$ Tetsuo Ohmachi, ${ }^{1}$ Akira Wakui, ${ }^{3}$ Ryunosuke Kanamaru ${ }^{3}$ and Minro Watanabe ${ }^{1,4}$ \\ ${ }^{\prime}$ Department of Cancer Chemotherapy and Prevention, ${ }^{2}$ Department of Internal Medicine and \\ ${ }^{3}$ Department of Clinical Cancer Chemotherapy, The Research Institute for Tuberculosis and Cancer, \\ Tohoku University, 4-I Seiryomachi, Aoba-ku, Sendai 980
}

\begin{abstract}
Cytochrome P450IIE1 (P450IIE1) is involved in metabolic activation of carcinogenic nitrosamines, aniline and benzene. We detected a restriction fragment length polymorphism of the human P450IIE1 gene with the restriction endonuclease DraI. The population was thus divided into three genotypes, namely, heterozygotes (CD) and two forms of homozygotes (CC and DD). The distribution of these genotypes among lung cancer patients differed from that among controls with statistical significance of $P<0.05\left(\chi^{2}=7.01\right.$ with 2 degrees of freedom). This result strongly suggests that host susceptibility to lung cancer is associated with the DraI polymorphism of the P450IIE1 gene.
\end{abstract}

Key words: Cytochrome P450IIE1 - Nitrosamine metabolism - Lung cancer - Restriction fragment length polymorphism

Recently, interindividual differences in susceptibility to human cancer have been noted. One cause of this may be a polymorphic gene controlling metabolic activation of environmental carcinogens, giving rise to interindividual variation in the production of more potent forms. ${ }^{1,2)}$

Nitrosamines constitute an important group of environmental carcinogens, and studies have suggested their relevance to human cancer. ${ }^{3)}$ Some of the nitrosamines, such as $\mathrm{N}$-nitrosodimethylamine, are metabolically activated by the cytochrome P450 enzyme P450IIE1. ${ }^{4-7)}$ Thus, differences in the genotypes or phenotypes of P450IIE $1^{5}$ may be responsible for variations in host susceptibility to cancers caused by nitrosamines. It is remarkable that the protein levels and activities of the human P450IIE1 have been shown to vary among liver samples, though no correlation of these phenotypic differences with susceptibility to cancer has yet been indicated. ${ }^{6,7)}$

To investigate the association of the genotypes of the P450IIE1 gene and susceptibility to cancer, we searched for restriction fragment length polymorphisms (RFLPs) of the gene. We detected an RFLP of the human P450IIE1 gene for the restriction endonuclease $\mathrm{DraI} .{ }^{8}$ In this study, we examined the genotypes of the DraI polymorphism in cancer patients and in controls to determine the frequency of each genotype in each group.

The study population consisted of 56 controls and 69 cancer patients. Controls were chosen from the popula-

\footnotetext{
${ }^{4}$ To whom correspondence should be addressed.

${ }^{5}$ The abbreviations used are: P450IIE1, cytochrome P450IIE1; RFLP, restriction fragment length polymorphism.
}

tion without known history of cancer. Cancer patients were divided into two groups: group A (47 lung cancer patients) and group B (22 patients with cancers at other sites). The lung cancer patients had a definite diagnosis proven by histology or cytology from samples obtained at bronchoscopy. Group B included patients of malignant lymphoma (2), chondrosarcoma (1), malignant fibrous histiocytoma (1) and malignant paraganglioma (1). The cancer sites of the other patients in group B were esophagus (5), colon or rectum (3), stomach (2), gallbladder (2), breast (2), parotid gland (1), urinary bladder (1) and nasopharyngeal tissue (1).

Blood $(7-15 \mathrm{ml})$ was obtained from each person and was used to isolate leukocyte DNA. Ten $\mu \mathrm{g}$ of leukocyte DNA was digested overnight with 24 units of $D r a I$ (Takara Shuzo, Kyoto) at $37^{\circ} \mathrm{C}$. The products were separated by electrophoresis at $60 \mathrm{~V}$ in $1 \%$ agarose and blotted onto a nitrocellulose membrane (Schleicher \& Schuell, Dassel, Germany) for Southern hybridization. ${ }^{9)}$ The blotted DNA fragments were then hybridized with the cDNA probe $\lambda \mathrm{hPD} 4^{(0)}$ (Fig. 1), labeled with ${ }^{32} \mathrm{P}$ dCTP (Amersham, Amersham, UK) using random oligonucleotide primers (Boehringer Mannheim, Mannheim, Germany). Washing and autoradiography were performed. Fragment sizes were determined by co-electrophoresis with HindIII-digested $\lambda$ DNA.

DraI detected two invariant bands at $2.3 \mathrm{~kb}$ and $1.2 \mathrm{~kb}$ and a two-allele polymorphism with bands at $5.5 \mathrm{~kb}(\mathrm{C})$ or $4.1 \mathrm{~kb}(\mathrm{D})$, as shown in Fig. 2. The population was thus divided into three genotypes, namely, heterozygotes (CD) and two forms of homozygotes (CC and DD). 


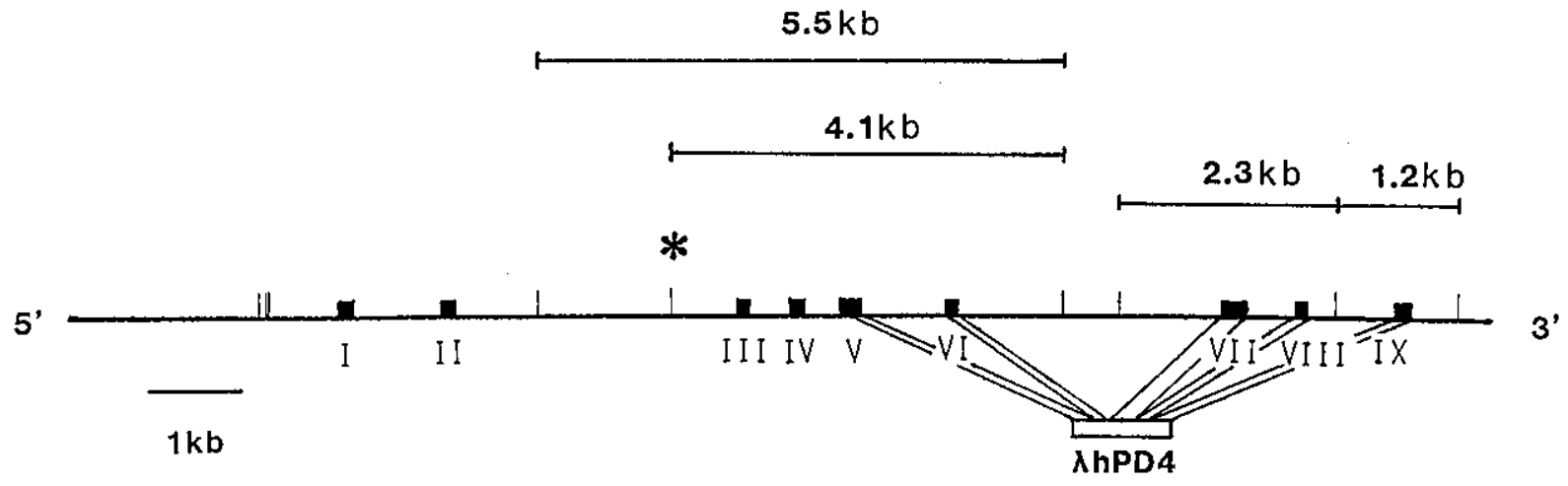

Fig. 1. Map of DraI cleavage sites in the human P450IIE1 gene. Solid boxes represent exons. * denotes the DraI site for the polymorphism. The four DNA fragments indicated above the map correspond to the bands detected by Southern hybridization. The DNA probe used, $\lambda \mathrm{hPD} 4$, contains a sequence of $1.0 \mathrm{~kb}$ at the $3^{\prime}$ end of the human P450IIE1 cDNA.

Table I. Distribution of the Genotypes of the DraI Polymorphism at P450IIE1 Gene among Various Populations

\begin{tabular}{|c|c|c|c|c|}
\hline \multirow{2}{*}{ Population } & \multicolumn{3}{|c|}{ Genotype } & \multirow{2}{*}{ Total } \\
\hline & $\mathrm{CC}$ & $\mathrm{CD}$ & DD & \\
\hline Control & 6 & 17 & 33 & 56 \\
\hline Lung cancer $(\mathrm{A})$ & 0 & 22 & 25 & 47 \\
\hline Squamous cell carcinoma & 0 & 7 & 7 & 14 \\
\hline Small cell carcinoma & 0 & 6 & 7 & 13 \\
\hline Large cell carcinoma & 0 & 3 & 3 & 6 \\
\hline Adenocarcinoma & 0 & 6 & 8 & 14 \\
\hline Other cancers $(\mathrm{B})^{a)}$ & 1 & 12 & 9 & 22 \\
\hline
\end{tabular}

a) Details are shown in the text.

Because the entire gene had been sequenced, ${ }^{11)}$ we were able to assign the origin of the RFLP at the second intron of the human P450IIE1 gene (Fig. 1).

Table I shows the distribution of the three genotypes of the DraI polymorphism of the P450IIE1 gene in each group. In the control group, the distribution of the genotypes was in Hardy-Weinberg equilibrium, gene frequencies being 0.26 for allele $C$ and 0.74 for allele $D$. The distribution of the genotypes among lung cancer patients (group A) was different from that among controls with statistical significance of $P<0.05\left(\chi^{2}=7.01\right.$ with 2 degrees of freedom). This strongly suggests that the Dral polymorphism of the P450IIE1 gene is associated with host susceptibility to lung cancer. On the other hand, no difference in the frequencies of the genotypes was found between other cancer patients (group B) and controls.

In lung cancer patients, the frequency of the $\mathrm{CC}$ genotype seems disproportionately low compared with controls. However, since we analyzed only a small

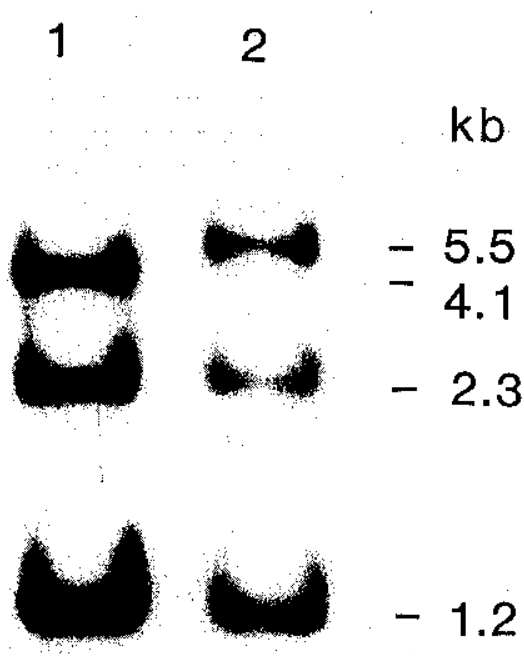

Fig. 2. RFLP of the human P450IIE1 gene with DraI using the cDNA probe $\lambda \mathrm{hPD} 4$. Lane 1 denotes a homozygote for allele D, and Lane 2 a homozygote for allele C.

number of patients, the relation of the $\mathrm{CC}$ genotype to susceptibility to lung cancer remains to be investigated. Since the polymorphism is caused by the presence or absence of a DraI site (TTT/AAA) in the intron of the gene, as was stated above, this mutation, as such, may not affect the expression of the gene. It may, however, be linked to another mutation in the same gene involved in the structure or regulation of the gene products. This critical mutation might affect host susceptibility to cancer through altering the metabolism of nitrosamines or other carcinogens occurring in the environment. It is also possible that the P450IIE1 gene flanks an oncogene, 
tumor suppressor gene, or the structural or regulatory genes for other P450s, such as the $A h$ locus.

Kawajiri et al. recently reported the association between susceptibility to lung cancer and RFLP of the P450IA1 gene, ${ }^{2)}$ though others reported negative results in studies with Caucasian populations. ${ }^{12)}$ The P450IA1 enzyme is known to metabolically activate aromatic hydrocarbons. Both nitrosamines and aromatic hydrocarbons are known to occur in tobacco smoke, and the correlation between exposure to tobacco smoke and lung cancer has been established epidemiologically. About $75 \%$ of the lung cancer patients we studied here had a positive history of cigarette smoking. We note, on the other hand, that nitrosamines occur in some kinds of food and are also formed in vivo from their precursors, ${ }^{3)}$ suggesting that nitrosamines from these sources may also cause various human cancers.

\section{REFERENCES}

1) Nebert, D. W. Genes encoding drug-metabolizing enzymes: possible role in human disease. In "Phenotypic Variation in Populations," ed. A. D. Woodhead, M. A. Bender and R. C. Leonard, pp. 45-64 (1988). Plenum Press, New York.

2) Kawajiri, K., Nakachi, K., Imai, K., Yoshii, A., Shinoda, $\mathrm{N}$. and Watanabe, $\mathrm{J}$. Identification of genetically high risk individuals to lung cancer by DNA polymorphisms of the cytochrome P450IA1 gene. FEBS Lett., 263, 131-133 (1990).

3) Bartsch, H. and Montesano, R. Relevance of nitrosamines to human cancer. Carcinogenesis, 5, 1381-1393 (1984).

4) Hong, J. and Yang, C. S. The nature of microsomal $\mathrm{N}$-nitrosodimethylamine demethylase and its role in carcinogen activation. Carcinogenesis, 6, 1805-1809 (1985).

5) Wrighton, S. A., Thomas, P. E., Ryan, D. E. and Levin, W. Purification and characterization of ethanol-inducible human hepatic cytochrome P-450HLj. Arch. Biochem. Biophys., 258, 292-297 (1987).

6) Yoo, J.-S. H., Guengerich, F. P. and Yang, C. S. Metabolism of $\mathrm{N}$-nitrosodialkylamines by human liver microsomes. Cancer Res., 48, 1499-1504 (1988).

7) Wrighton, S. A., Thomas, P. E., Molowa, D. T., Haniu, M., Shively, J. E., Maines, S. L., Watkins, P. B., Parker, G., Mendez-Picon, G., Levin, W. and Guzelian, P. S. Characterization of ethanol-inducible human liver $\mathrm{N}$ -
The association of the polymorphism with susceptibility to cancers at other sites remains to be investigated, since we analyzed only a small number of samples in this study. From the viewpoint of cancer prevention, it is desirable to identify high-risk groups. Further studies with a larger number of samples are being carried out to confirm and extend our results.

This work was supported by Grants-in-Aid for Cancer Research from the Ministry of Education, Science and Culture of Japan, and by grants from the Princess Takamatsu Cancer Research Fund and Smoking Research Foundation. We thank Dr. T. Kamataki and Dr. M. Komori (Faculty of Pharmaceutical Sciences, Hokkaido University) for providing the cDNA probe; and Dr. C. Ishioka and Dr. H. Shibata for their support during this study.

(Received November 10, 1990/Accepted January 11, 1991)

nitrosodimethylamine demethylase. Biochemistry, 25, 6731-6735 (1986).

8) Uematsu, F., Kikuchi, H., Ohmachi, T., Sagami, I., Motomiya, M., Kamataki, T., Komori, M. and Watanabe, M. Two common RFLPs of the human CYP2E gene. Nucleic Acids Res., 19 (1991), in press.

9) Southern, E. M. Detection of specific sequences among DNA fragments separated by gel electrophoresis. J. Mol. Biol., 98, 503-517 (1975).

10) Komori, M., Nishio, K., Fujitani, T., Ohi, H., Kitada, M., Mima, S., Itahashi, K. and Kamataki, T. Isolation of a new human fetal liver cytochrome P450 cDNA clone: evidence for expression of a limited number of forms of cytochrome P450 in human fetal livers. Arch. Biochem. Biophys., 272, 219-225 (1989).

11) Umeno, M., McBride, O. W., Yang, C. S., Gelboin, H. V. and Gonzalez, F. J. Human ethanol-inducible P450IIE1: complete gene sequence, promoter characterization, chromosome mapping, and cDNA-directed expression. Biochemistry, 27, 9006-9013 (1988).

12) Tefre, T., B $\phi$ rresen, A. L., Ryberg, D., Haugen, A. and $\mathrm{Br} \phi \mathrm{gger}, \mathrm{A}$. Allele association studies of the P450IA1 and P450IID1 DNA-polymorphisms in lung cancer patients and controls. Proc. 7th Int. Symp. on Microsomes and Drug Oxidations, 51 (1990). 